\title{
Exploring the attitudes of medical faculty members and students in Pakistan towards plagiarism: a cross sectional survey
}

Farooq A Rathore, Ahmed Waqas, Ahmad Marjan Zia, Martina Mavrinac, Fareeha Farooq

Objective:The objective of this survey was to explore the attitudes towards plagiarism of faculty members and medical students in Pakistan.

Methods:The attitudes toward plagiarism questionnaire (ATPQ) was modified and distributed among 550 medical students and 130 faculty members in 7 medical colleges of Lahore and Rawalpindi. Data was entered in the SPSS v.20 and descriptive statistics were analyzed. The questionnaire was validated by principal axis factoring analysis.

Results:Response rate was $93 \%$ and $73 \%$ respectively. Principal axis factoring analysis confirmed one factor structure of ATPQ in the present sample. It had an acceptable Cronbach's alpha value of 0.73 . There were 421 medical students (218 (52\%) female, 46\% $3^{\text {rd }}$ year MBBS students, mean age of $20.93 \pm 1.4$ years) and 95 faculty members $(54.7 \%$ female, mean age $34.5 \pm 8.9$ years). One fifth of the students (19.7\%) trained in medical writing $(19.7 \%)$, research ethics $(25.2 \%)$ or were currently involved in medical writing (17.6\%). Most of the faculty members were demonstrators (66) or assistant professors (20) with work experience between 1-10 years. Most of them had trained in medical writing (68), research ethics (64) and were currently involved in medical writing (64). Medical students and faculty members had a mean score of 43.21 (7.1) and 48.4 (5.9) respectively on ATPQ. Most of the respondents did not consider that they worked in a plagiarism free environment and reported that self-plagiarism should not be punishable in the same way as plagiarism. Opinion regarding leniency in punishment of younger researchers who were just learning medical writing was divided.

Conclusions:The general attitudes of Pakistani medical faculty members and medical students as assessed by ATPQ were positive. We propose training in medical writing and research ethics as part of the under and post graduate medical curriculum. 
2 Exploring the attitudes of medical faculty members and students in Pakistan towards

3 plagiarism: a cross sectional survey.

4 Authors

5 Dr Farooq Azam Rathore ${ }^{1}$, Ahmed Waqas ${ }^{2}$, Ahmed Marjan Zia², Martina Mavrinac ${ }^{3}$, Dr Fareeha

6 Farooq $^{4}$

$7{ }^{1}$ Assistant Professor, Department of Rehabilitation Medicine, Combined Military Hospital,

8 Lahore Cantt

$9 \quad{ }^{2} \mathrm{CMH}$ Lahore Medical and Dental College, Lahore Cantt.

$10{ }^{3}$ Department for Medical Informatics, University of Rijeka, School of Medicine, Rijeka, Croatia

$11{ }^{4}$ Department of biochemistry, Fatima Memorial Hospital Medical College, Shadman, Lahore

12 Corresponding Author

13 Ahmed Waqas ${ }^{2}$

14 Email: ahmedwaqas1990@hotmail.com

15 Contact: $+92-03434936117$

16 Conflict of interest: None

17 Financial aid: none 
Abstract word count: 286

Article word count: 3184 (excluding references and tables)

\section{Declaration:}

22 Presented as Poster presentation by AW at the 3rd Annual conference of association for

23 excellence in medical education conference (AEME 2014), 7th -9th March 2014, University of

24 health sciences, Lahore. 
Abstract

27 Objective: The objective of this survey was to explore the attitudes towards plagiarism of

28 faculty members and medical students in Pakistan.

29 Methods: The attitudes toward plagiarism questionnaire (ATPQ) was modified and distributed among 550 medical students and 130 faculty members in 7 medical colleges of Lahore and Rawalpindi. Data was entered in the SPSS v.20 and descriptive statistics were analyzed. The questionnaire was validated by principal axis factoring analysis.

Results: Response rate was $93 \%$ and $73 \%$ respectively. Principal axis factoring analysis confirmed one factor structure of ATPQ in the present sample. It had an acceptable Cronbach's alpha value of 0.73 . There were 421 medical students $\left(218(52 \%)\right.$ female, $46 \% 3^{\text {rd }}$ year MBBS students, mean age of $20.93 \pm 1.4$ years $)$ and 95 faculty members $(54.7 \%$ female, mean age $34.5 \pm 8.9$ years). One fifth of the students $(19.7 \%)$ trained in medical writing $(19.7 \%)$, research ethics $(25.2 \%)$ or were currently involved in medical writing (17.6\%). Most of the faculty members were demonstrators (66) or assistant professors (20) with work experience between 1-10 years. Most of them had trained in medical writing (68), research ethics (64) and were currently involved in medical writing (64). Medical students and faculty members had a mean score of 43.21 (7.1) and 48.4 (5.9) respectively on ATPQ. Most of the respondents did not consider that they worked in a plagiarism free environment and reported that self-plagiarism should not be punishable in the same way as plagiarism. Opinion regarding leniency in punishment of younger researchers who were just learning medical writing was divided.

Conclusions: The general attitudes of Pakistani medical faculty members and medical students as assessed by ATPQ were positive. We propose training in medical writing and research ethics as part of the under and post graduate medical curriculum. 
Introduction

Plagiarism is defined as "the deliberate or reckless use of someone else's attention in biomedical writing. There has been an increase in the number of manuscripts published on plagiarism in the last one decade. However most of the work is from the developed nations of the world where research training is usually imparted at undergraduate level. In comparison, the research output from developing countries including Pakistan is low, so there is a need to promote research education and training in these regions.

Plagiarism has been documented and reported mainly from the developed countries with a better research environment, stronger training and more common use of plagiarism detection software. With advancement in plagiarism detection software, an ever-increasing number of plagiarized papers are being recognized, often leading to their retraction from the journals. Employing plagiarism detection software and manual verification, Bazdaric et al. reported the prevalence of plagiarized manuscripts among manuscripts submitted to Croatian medical journal during 20092010 to be $11 \%(85 / 754)$ (Bazdaric et al., 2012). A recent study of 2,047 cases of retracted papers from PubMed indexed journals reported an encouraging trend in recognition and retraction of plagiarized articles (Steen, Casadevall \& Fang, 2013). While these statistics are encouraging, but most of the time detection after publication it cannot prevent the damage that had already been done to science if plagiarized articles had already been cited. Retraction watch 
(http://retractionwatch.com/) is a blog which documents plagiarism, fabrication and retractions in the scientific community. It mentions a high number of research articles based on fake data, image manipulation, self-plagiarism, fake peer reviews and disputed authorships that are being retracted frequently from reputable journals (Marcus \& Oransky, 2014). Unfortunately, this misconduct not only involves novice researchers, doctorate and post doc scholars from middle income countries but also scientists and institutes from Europe, Americas and Japan enjoying international fame and prestige. Plagiarizing research work often leads to great setbacks in one's careers.

Although the prevalence of intentional plagiarism in low resource countries has not been reported, it can be argued that it might be more prevalent in countries like Pakistan due to "a general lack of information regarding plagiarism among medical students and faculty members" (Shirazi, Jafarey \& Moazam, 2010). However, the probability of intentional plagiarism both in the faculty and students also cannot be ignored. Prevalence of plagiarism is very hard to measure but the investigations of attitudes can also give us an insight in this phenomenon. This opinion is reinforced by Ajzen's theory of planned behavior which assumes that human beings are rational: A preceding intention entailing attitudes, subjective norms and perceived behavioral control, is necessary to perform a specific behavior (Ajzen, 1991).

A number of studies conducted in Romania (Badea-Voiculescu, 2013), Pakistan (Shirazi, Jafarey \& Moazam, 2010), Croatia (Mavrinac et al., 2010), Norway (Hofmann, Myhr \& Holm, 2013) and Iran (Ghajarzadeh et al., 2012; Ghajarzadeh et al., 2013) have reported a high prevalence of positive attitude among both students and faculty members towards plagiarism 
93 Ghias' survey on academic dishonesty in Pakistani medical students, reported a high prevalence

94 of medical students who were involved in copying verbatim from internet or published sources,

95 senior peers, class mates with or without their consent, fabricating data to show desirable results,

96 forging professors' signatures, faking health certificates to justify absence and other such

97 behaviors (Ghias et al., 2014). Poorolajal et al. reported an overall prevalence of plagiarism as

$9838 \%$ in an Iranian University (Poorolajal et al., 2012). This trend decreased by $13 \%$ with one unit

99 increase in knowledge of plagiarism. Similarly in India, a high prevalence of plagiarism was

100 attributed to pressure to publish and lack of facilities and funding in private institutions (Singh \&

101 Guram, 2014). This calls for serious educational reforms and implementation of strict policies

102 regarding plagiarism not only in university curriculum but also in lower grades.

103 Although many studies specifically on plagiarism have been published abroad, in Pakistan

104 research on this specific subject is lacking. This study was conducted on a relatively large sample

105 of medical students and faculty in seven private and public medical colleges. The Attitudes

106 Towards Plagiarism Questionnaire (ATPQ) was chosen to explore knowledge and attitudes of

107 faculty members and medical students towards plagiarism. The original ATPQ had 29 items

108 assessing positive, negative and subjective attitudes towards plagiarism (Mavrinac et al., 2010).

109 This questionnaire was based on Azjen's theory of planned behavior and has been validated in

110 Croatia (Mavrinac et al., 2010). Subsequently it was extensively used in other countries for

111 example, India (Gomez, Nagesh \& Sujatha, 2014), Iran (Ghajarzadeh et al., 2012) and Romania

112 (Badia-Voiculescu, 2013). 
114 The current study was designed with two aims: 1) To explore the attitudes of Pakistani medical

115 students and faculty towards plagiarism 2) To study the association between formal training in

116 research ethics, medical writing and attitudes towards plagiarism.

\section{Material and methods}

A cross sectional survey was designed and conducted in three private and four public

121 medical colleges in Lahore and Rawalpindi (August 2013- January 2014). Permission was obtained from the Institutional review board of $\mathrm{CMH}$ Lahore Medical College.

\section{Questionnaire}

124 To collect data, we used a questionnaire divided in of three sections. The first section

125 documented demographics. The second had questions on participants' interest and formal

126 training in research methodology, research ethics and involvement in medical writing. The third

127 section consisted of modified version of ATPQ (Mavrinac et al., 2010). The questionnaire was

128 used with permission and modified for our study population. It was not translated from the

129 original English version, as English is the language of instruction in all medical schools in

130 Pakistan.

\section{Pilot Survey}

132 A pilot survey was conducted and feedback received from faculty and students during the pilot

133 survey resulted in removal of 4 items in order to adopt the scale to Pakistani culture and

134 academic environment. It was further modified from five-point to a three-point Likert type scale 
135 (agree (coded as 3), neutral (coded as 2) and disagree (coded as 1)) to facilitate the responses.

136 Factorial analysis was performed to confirm the factor structure of the modified questionnaire.

\section{Participants}

138 Convenience sampling technique was employed. Sample size was calculated at 95\% confidence

139 level and 5\% confidence interval. Questionnaires were distributed among 550 medical students

140 and 130 faculty members in 07 public and private medical colleges of Lahore and Rawalpindi.

141 All participants read and signed informed consent forms, which were returned with each

142 completed questionnaire. Forms were personally distributed and collected by two of the authors

143 (AM, AW). Response rate was $93.45 \%$ and $73.05 \%$ for medical students and faculty members

144 respectively. Ninety three forms were discarded (Incomplete or missing data, duplicate entries 145 etc.).

\section{Data Analysis}

147 Data was analyzed by SPSS v 20. To confirm the factor structure of the questionnaire principal

148 axis factoring analysis was used. The reliability of the questionnaire was calculated using

149 Cronbach's alpha.

150 Descriptive and inferential statistical test were employed to analyze the data. An independent

151 sample T-test was run to analyze associations between formal training in research ethics, medical

152 writing (yes/no) and scores on ATPQ (continuous variables). Chi Square goodness-of-fit

153 statistics was run to analyze association between score ranges of ATPQ and respondent group

154 (faculty/student). One way ANOVA was run between scores on ATPQ and job designation, 155 experience and education level of faculty members. 
156

157

158

159

160

161

162

163

164

165

166

167

168

169

170

171

172

173

174

175

176

\section{Results}

\section{Characteristics of respondents:}

Characteristics of respondents and their training in medical writing are given in Table 1. There were 421 medical students and 95 faculty members. Most of the students were females $218(51.8 \%)$ and $3^{\text {rd }}$ year MBBS students $192(45.6 \%)$.

\section{Questionnaire validation}

Principal axis factor analysis was run to confirm the factor structure of the Pakistan version of the ATPQ. However, unlike Croatian version of ATPQ, the three factor structure was not confirmed. In present study, one factor structure was determined by the Scree-test (Figure 1), interpretability criteria and the reliability of the factor calculated with Cronbach's alpha ( $\alpha=$ 0.73). The obtained factor represents an overall attitude towards plagiarism consisting of positive attitudes, negative attitude and subjective norms. Table 2 presents the factor structure of the Attitudes Towards Plagiarism Questionnaire with factor loadings. Items 11, 12, 13 are not included in the final factor structure and analyses because of low factor loading $(<0.10)$. The one factor structure explained $10.93 \%$ of variance in the questionnaire and average Inter-Item Correlation was .112. Total scores were obtained by summing all the statements. The mean score was divided into 3 ranges by 2 cut offs at $33.33 \%, 66.66 \%$ of scores on ATPQ. Thus, scores on modified ATPQ were divided into three categories; low $(<42)$, moderate $(43-47)$ and high $(>$ 48). According to this scale, increasing score represents a positive leaning towards plagiarism.

\section{$\underline{\text { Attitudes towards plagiarism }}$}


177 Independent sample T-test revealed that those medical students who had been formally trained in

178 medical writing were associated with low scores on ATPQ (Mean group $1=43.61(\mathrm{SD}=6.92)$,

179 mean group $2=41.58(\mathrm{SD}=7.51), \mathrm{P}<.05)$, whereas students who were trained in research ethics

$180(\mathrm{P}=.936)$ or were currently writing a research paper $(\mathrm{P}=.674)$ did not differ from their

181 counterparts on ATPQ scores.

182 The frequency distribution of medical students and faculty members between score ranges is

183 given in table 3. According to Chi Square goodness-of-fit statistics, a statistically higher

184 percentage of faculty members had ATPQ scored in moderate 32 (33.7\%) or high category 49

$185(51.6 \%)$ than low category $14(14.7 \%)(\mathrm{P}<.001)$. A higher proportion of students had ATPQ

186 scores in the low $(45.1 \%)$ or moderate category $(26.6 \%)$ than in the high category $(28.3 \%)(\mathrm{P}<$

$187.001)$

Pearson Chi-Square revealed that faculty with foreign qualifications had better formal training in research ethics $(\mathrm{p}-<0.05)$. According to it, all of the faculty member who were educated abroad $(n=15)$ had received formal education in research ethics. More than half $(61.2 \%)$ of faculty members educated in Pakistan had a formal education in research ethics.

No statistically significant difference was found between mean scores on ATPQ scores and job designation $(\mathrm{P}=0.734)$, experience levels $(\mathrm{P}=0.208)$ education level $(\mathrm{P}=.068)$. Independent sample $\mathrm{T}$ test revealed no significant association between ATPQ scores and training in research ethics $(\mathrm{P}=.87)$, medical writing $(\mathrm{P}=.17)$ or current involvement in medical writing. $(\mathrm{P}=.99)$. modified ATPQ. 
Discussion

The study revealed that the majority of medical students $(55 \%)$ and faculty members $(82.7 \%)$ had moderate or high scores on the ATPQ. This represents their approval of plagiarism. This finding is in consonance with previous studies conducted in Pakistan.

Lower scores on ATPQ in medical students were associated with training in medical writing whereas ATPQ scores were not significantly associated with formal education in research ethics or current involvement in medical writing. Factor analysis revealed a one-factor structure representing attitude towards plagiarism with 22 statements and good reliability. This version of ATPQ is valid and reliable for use on Pakistani population.

Shirazi et al. have attributed lack of training in research methodology and referencing techniques among Pakistani students and faculty rather than malice as a cause of plagiarism in most cases

212 (Shirazi, Jafarey \& Moazam, 2010). Shashok has also noted that many cases of plagiarism are unintentional and arise from lack of knowledge of citation practices, pressure to increase publication output, and inability to write and communicate ideas in English (which may lead to copy-pasting to improve use of language in the manuscript) (pers comm. Shashok, 2011). Formal training in research methodology, medical and publication ethics at the undergraduate level is generally lacking in Pakistan. Even the faculty members are not clear about the definition, types and implications of plagiarism and unethical practices in medical writing and research. The mandatory training workshops of the college and physicians and surgeons in 
220 Pakistan for the trainees and supervisors do not adequately address plagiarism and other

221 unethical practices in medical research and writing.

222 Only about one quarter of students in our sample were formally trained in medical writing and

223 research ethics. These findings are consistent with those of Shirazi et al. who have attributed lack

224 of knowledge of proper referencing and citing as a cause of plagiarism in medical students

225 (Shirazi, Jafarey \& Moazam, 2010). In contrast to students, most of the faculty members had

226 received formal training and education in research ethics and medical writing. This was probably

227 due to involvement of the faculty in the continuing medical education, self-directed learning and

228 the recent revision of faculty promotion rules by the Pakistan Medical and Dental Association

229 (PMDC) which mandates the faculty members to write a certain number of articles for

230 promotions. The medical students who had been trained in medical writing or were currently

231 involved in medical writing had a low tendency towards plagiarism. In our study, year of study

232 did not affect attitudes towards plagiarism in medical students. These findings favor our

233 hypothesis that formal education of medical students would decrease the prevalence of

234 plagiarism. However, the evidence of efficacy of educational interventions on attitude towards

235 plagiarism is rather confusing. An online case study discussing plagiarism by adult learners

236 found no significant association between the incidence of plagiarism and cheating and

237 educational interventions on policies related to academic honesty (Jocoy \& Dibiase, 2006).

238 However, imparting information related to policies on academic honesty immediately before

239 examinations lowered the incidence of cheating behaviors (Kerkvliet \& Sigmund, 1999).

240 Similarly, Anderson et al. reported no significant association between attending formal courses

241 on research ethics and academic dishonesty (Anderson et al., 2007). However, it should be noted 
242 that results of these studies were from developed countries, therefore, these results might not be

243 applicable in Pakistan where cultural and academic environment is very different.

Most of our sample of faculty members $(69.4 \%)$ were less experienced demonstrators in medical colleges who did not have postgraduate degrees or fellowships yet. This highlights the need for continuing medical education programs and for interventions on research ethics and medical writing. Ghajarzadeh et al. reported similar trends in ATPQ scores of Iranian faculty members (Ghajarzadeh et al., 2012). These arguments are in consonance with Shirazi et al., where less than $30 \%$ of the faculty members had correct knowledge of copyright rules, referencing or use of quotation marks (Shirazi, Jafarey \& Moazam, 2010).

Most of the students disagreed with the statement that they worked in a plagiarism free environment. Such high "perceived" prevalence of plagiarism among medical students might be rooted in the learning styles of most Pakistani students who, unlike students at Western institutions, are more involved in rote and teacher-centered learning (Introna et al., 2003). Many students tend to copy verbatim from learning resources or others' work mainly due to insufficient language proficiency (Vessal \& Habibzadeh, 2007). This behavior can be discouraged by increasing the awareness and use of plagiarism detection software among both faculty and students. As confirmed in our study, a high percentage of students resort to cheating behavior because they haven't been caught yet. This trend was also explored by another study which reported a very low awareness about existence of plagiarism detection software in Pakistani

262 university students (Ramzan et al., 2012).

263 It is essential to understand its etiology if one is to decrease the practice of plagiarism. In a 
265 having plagiarized at least once in their life (Shirazi, Jafarey \& Moazam, 2010). This supports

266 our findings where only $24.2 \%$ of the medical faculty and $20.4 \%$ of medical students agreed that

267 they worked in a plagiarism free environment. The causes of this evil practice in Pakistani

268 medical faculty are many folds. PMDC has laid down strict criteria of qualification, teaching

269 experience and research experience for promotion in academic ranks. Promotion of an assistant

270 professor to rank of associate professor and to professor requires at least 3 and 5 publications

271 respectively in PMDC indexed journals (PMDC, 2011). In our study, a majority of the faculty

272 members and students agreed that approaching deadlines gave them a right to plagiarize

273 (supplementary file 1). Thus, approaching deadlines (pressure to publish) and promotions in

274 academia have led to a focus on quantity rather than quality of research products.

275 A majority of the medical students agreed that young researchers should receive milder

276 punishment, but medical faculty had a mixed opinions. A majority of the respondents in our

277 survey agreed that they are tempted to plagiarize because everyone else is doing it. Therefore, in

278 our opinion the identities of the plagiarists should be brought to light to set an example for the

279 academic community and keep plagiarism in check.

280 Proper policies should be devised by the stakeholders and training modules on research and

281 medical writing should be introduced in medical curriculum. The Higher Education Commission,

282 Pakistan (HEC), Pakistan Medical and Dental Council, Pakistan (PMDC) and College of

283 Physicians and Surgeons, Pakistan (CPSP) should facilitate the medical colleges and universities

284 to train and establish ethics review committees and intuitional review boards. The medical

285 colleges should invest in plagiarism detection software and make it available to their students,

286 trainees and faculty members. Even if an institute doesn't subscribe to a paid plagiarism

287 detection software there are many free alternatives available (Rathore \& Farooq, 2014). 
288 Workshops, seminars, invited lectures should be arranged specifically to address this issue.

289 Dedicated modules on research methodology, analytical and referencing techniques should be

290 integrated in undergraduate medical curriculum to further develop the research environment in

291 Pakistan. This calls for a revision of undergraduate and postgraduate curriculum and faculty

292 training with an emphasis in teaching the current best practices and ethics of medical research

293 and writing.

\section{Limitations}

295 The cross-sectional design of this study limits inferences about causality and temporality. Use of

296 self-administered questionnaires may lead to information bias. The present study is based on an

297 adequate sample size but it was collected using convenience sampling approach. Therefore, its

298 results cannot be generalized to the whole Pakistani population or medical students or faculty

299 members.

\section{Conclusions}

301 The general attitudes of Pakistani medical faculty members and medical students as assessed by

302 ATPQ were approving towards plagiarism. There is a lack of training in biomedical ethics and

303 good practices in medical writing. We propose training in medical writing and research ethics as

304 part of the under- and post-graduate medical curriculum. Faculty should keep itself updated

305 about the latest policies regarding plagiarism inside the country and abroad. Steps should be

306 taken by PMDC, CPSP and HEC to raise awareness about this menace in Pakistan.

\section{Acknowledgement:}


The authors thank Sana Gulraiz; student at Services Institute of Medical Sciences, Lahore and Bilal Gujjar; student at Sheikh Khalifa Bin Zayed Al Nahyan Medical and Dental College,

Lahore, for their help in collecting data for this project. The authors also thank Andrew J. Haig,

M.D; Professor of Physical Medicine and Rehabilitation at The University of Michigan, USA.

\section{References}

Ajzen I. 1991. The theory of planned behavior. Orgnizational Behavior and Human Decision Processes 50:179-211.

Anderson MS, Horn AS, Risbey KR, Ronning EA, De Vries R, Martinson BC. 2007. What do mentoring and training in the responsible conduct of research have to do with scientists' misbehavior? Findings from a National Survey of NIH-funded scientists. Academic Medicine 82(9):853-60.

Badea-Voiculescu O. 2013. Attitude of Romanian medicine students towards plagiarism. Romanian Journal of Morphology and Embryology 54(3 Supplement):907-8.

Baždarić K, Bilić-Zulle L, Brumini G, Petrovečki M. 2012. Prevalence of Plagiarism in Recent Submissions to the Croatian Medical Journal. Science and engineering ethics 18 (2); 22339.

Pakistan medical \& dental council. 2011. Regulations for the appointment of faculty professorial staff / examiners / principals / deans / administrative staff IN undergraduate and postgraduate medical and dental institutions of Pakistan 2011.

Ghajarzadeh M, Norouzi-Javidan A, Hassanpour K, Aramesh K, Emami-Razavi SH. 2012. Attitude toward plagiarism among Iranian medical faculty members. Acta Medica Iranica 50(11):778-81.

Ghajarzadeh M, Hassanpour K, Fereshtehnejad SM, Jamali A, Nedjat S, Aramesh K.. 2013. Attitude towards plagiarism among Iranian medical students. Journal of Medical Ethics 39(4):249. doi: 10.1136/medethics-2012-100560.

Ghias K, Lakho GR, Asim H, Azam IS, Saeed SA. 2014. Self-reported attitudes and behaviours of medical students in Pakistan regarding academic misconduct: a cross-sectional study. BMC Medical Ethics 15(1):43.

Hofmann B, Myhr AI, Holm S. 2013. Scientific dishonesty--a nationwide survey of doctoral students in Norway. BMC Medical Ethics 5;14:3. doi: 10.1186/1472-6939-14-3. 
Introna L, Hayes N, Blair L, Wood E. 2003. Cultural attitudes towards developing a better understanding of the needs of students from diverse cultural backgrounds relating to issues of plagiarism. Archived at http://online. northumbria.ac.uk/faculties/art/information_studies/Imri/Jiscpas/docs/external/lancsplagiari smreport. pdf.

Jocoy CL, DiBiase D. 2006. Plagiarism by adult learners online: a case study in detection and remediation. The International Review of Research in Open and Distance Learning. 7(1):115.

Kerkvliet J, Sigmund CL 1999. Can we control cheating in the classroom? The Journal of Economic Education Fall:331-43.

Marcus A, Oransky I. 2014. Retraction Watch [Internet]. Available from: http://retractionwatch.com/.

Mason PR. 2009. Plagiarism in scientific publications. The Journal of Infection in Developing Countries 3:1-4.

Mavrinac M, Brumini G, Bilić-Zulle L, Petrovečki M. 2010. Construction and Validation of Attitudes Toward Plagiarism Questionnaire. Croatian Medical Journal 60(4):269-73.

Poorolajal J, Cheraghi P, Doosti Irani A, Cheraghi Z, Mirfakhraei M. 2012. Construction of knowledge, attitude and practice questionnaire for assessing plagiarism. Iranian Journal of Public Health 41:54-58.

Ramzan M, Munir MA, Siddique N, Asif M. 2012. Awareness about plagiarism amongst university students in Pakistan. Higher Education 64(1):73-84.

Gomez MSS, Nagesh L, Sujatha BK. 2014. Assessment of the attitude towards Plagiarism among dental postgraduate students and faculty members in Bapuji Dental College and Hospital, Davangere - A cross sectional survey. IOSR Journal of Dental and Medical Sciences 13 (5); 1-6.

Shashok K. 2011. Authors, editors, and the signs, symptoms and causes of plagiarism. Saudi journal of anaesthesia 5(3):303-7. doi: 10.4103/1658-354X.84107.

Shirazi B, Jafarey AM, Moazam F. 2010. Plagiarism and the medical fraternity : A study of knowledge and attitudes. Journal of Pakistan Medical Association 60(4):269-73.

Singh HP, Guram N. 2014. Knowledge and Attitude of Dental Professionals of North India Toward Plagiarism. 6:6-11.

Steen RG, Casadevall A, Fang FC. 2013. Why has the number of scientific retractions increased? PLoSOne. 2013 Jul 8;8(7):e68397. doi: 10.1371/journal.pone.0068397. 
371 Vessal K, Habibzadeh F. 2007. Rules of the game of scientific writing: fair play and plagiarism. $372 \quad$ Lancet 369:641. 
Table $\mathbf{1}$ (on next page)

Demographic characteristics of medical students and faculty members $(n=516)$ 
Table 1:

\begin{tabular}{|c|c|c|c|}
\hline \multicolumn{2}{|l|}{ Variables } & Medical Students & Faculty Members \\
\hline \multirow{2}{*}{ Gender } & Male & $203(48.2 \%)$ & $43(45.3 \%)$ \\
\hline & Female & $218(51.8 \%)$ & $52(54.7 \%)$ \\
\hline \multirow[t]{4}{*}{ Designation } & Demonstrator & - & $66(69.4 \%)$ \\
\hline & Assistant Professor & - & $20(21.1 \%)$ \\
\hline & Associate Professor & - & $6(6.3 \%)$ \\
\hline & Professor & - & $3(3.2 \%)$ \\
\hline \multirow[t]{3}{*}{ Education } & MBBS/MD & - & $46(48.4 \%)$ \\
\hline & Masters Degree & - & $26(27.4 \%)$ \\
\hline & Fellowship & - & $19(20 \%)$ \\
\hline \multicolumn{2}{|c|}{ Education from abroad } & - & $15(15.8 \%)$ \\
\hline \multicolumn{2}{|c|}{ Median age (min-max) } & $21(17-28)$ & $32(23-61)$ \\
\hline \multicolumn{2}{|c|}{ Training in Medical writing } & $83(19.7 \%)$ & $68(71.6 \%)$ \\
\hline \multicolumn{2}{|c|}{ Training in research ethics } & $106(25.2 \%)$ & $64(67.4 \%)$ \\
\hline \multicolumn{2}{|c|}{ Currently writing an article } & $74(17.6 \%)$ & $64(67.4 \%)$ \\
\hline \multicolumn{2}{|c|}{ Mean score and SD on ATPQ } & $43.21(7.1)$ & $48.4(5.9)$ \\
\hline
\end{tabular}

Demographic

characteristic

s of medical

students and

faculty

members $(\mathrm{n}=$

516) 
Table 2 (on next page)

Factor structure of the Attitudes Towards Plagiarism questionnaire with factor loadings 


\section{TABLE 2. Factor structure of the Attitudes Towards Plagiarism questionnaire with factor loadings}

\begin{tabular}{|c|c|c|}
\hline \multicolumn{2}{|c|}{ Statements } & \multirow{2}{*}{$\begin{array}{l}\text { Factor } \\
\text { loading } \\
-0,39\end{array}$} \\
\hline 1. & $\begin{array}{l}\text { Since plagiarism is taking other people's words rather than tangible assets; it should NOT be considered as a serious } \\
\text { offence. }\end{array}$ & \\
\hline 2. & It is justified to use previous descriptions of a method, because the method itself remains the same. & $-0,23$ \\
\hline 3. & Self-plagiarism is not punishable because it is not harmful (one cannot steal from oneself). & $-0,39$ \\
\hline 4. & Plagiarized parts of a paper may be ignored if the paper is of great scientific value. & $-0,36$ \\
\hline 5. & Self-plagiarism should not be punishable in the same way as plagiarism is. & -0.13 \\
\hline 6. & Young researchers who are just learning the ropes should receive milder punishment for plagiarism. & -0.19 \\
\hline 7. & I could not write a scientific paper without plagiarizing. & -0.40 \\
\hline 8. & Short deadlines give me the right to plagiarize a bit. & -0.48 \\
\hline 9. & $\begin{array}{l}\text { It is justified to use one's own previously published work without providing citation in order to complete the current } \\
\text { work. }\end{array}$ & -0.39 \\
\hline 10. & Authors say they do NOT plagiarize, when in fact they do. & -0.20 \\
\hline 11. & *Plagiarists do not belong in the scientific community. & 0,09 \\
\hline 12. & *The names of the authors who plagiarize should be disclosed to the scientific community & 0,01 \\
\hline
\end{tabular}


13. *In times of moral and ethical decline, it is important to discuss issues like plagiarism and self-plagiarism.

14. A plagiarized paper does no harm to science.

15. Sometimes one cannot avoid using other people's words without citing the source, because there are only so many

ways to describe something

16. If a colleague of mine allows me to copy from her/his paper, I'm NOT doing anything bad, because I have his/her permission.

17. Those who say they never plagiarized are lying.

18. Sometimes I'm tempted to plagiarize, because everyone else is doing it (students, researchers, physicians).

19. I keep plagiarizing because I haven't been caught yet

20. I work (study) in a plagiarism-free environment.

21. Plagiarism is not a big deal.

22. Sometimes I copy a sentence or two just to become inspired for further writing.

23. I don't feel guilty for copying verbatim a sentence or two from my previous papers.

24. Plagiarism is justified if I currently have more important obligations or tasks to do.

25. Sometimes, it is necessary to plagiarize. 


\section{Table 3(on next page)}

Frequency distribution of medical students and faculty members in score ranges of ATPQ 
2 Table 3: Frequency distribution of medical students and faculty members in score ranges of 3 ATPQ

\begin{tabular}{|l|l|l|l|l|l|}
\hline Respondent & Low $(<42.0)$ & Moderate (43-47) & High $(>48)$ & Total (n) & $\chi^{2}$ value (P-value) \\
\hline Medical Student & $190(45.1 \%)$ & $112(26.6 \%)$ & $119(28.3 \%)$ & $421(100 \%)$ & $26.5(\mathrm{P}<.001)$ \\
\hline Faculty member & $14(14.7 \%)$ & $32(33.7 \%)$ & $49(51.6 \%)$ & $95(100 \%)$ & $19.3(\mathrm{P}<.001)$ \\
\hline
\end{tabular}


1

Scree plot for the obtained one factor structure

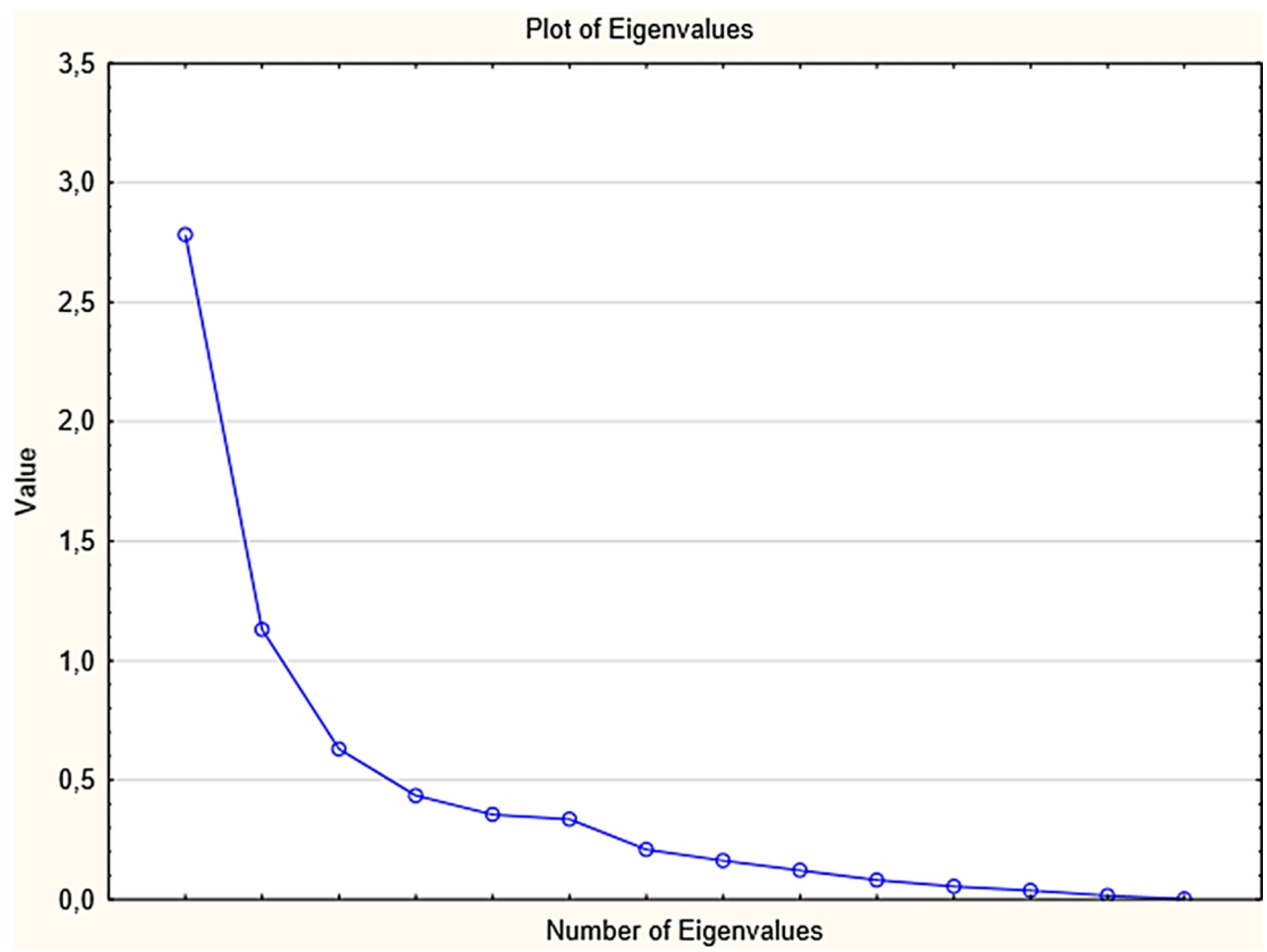

